\title{
OPINION
}

\section{Risk compensation theory should be subject to systematic reviews of the scientific evidence}

\author{
D C Thompson, R S Thompson, F P Rivara
}

\section{Background}

Many readers of Injury Prevention are quite familiar with the debate over bicycle helmet use. The core of this debate is the opinion on one side that helmets are effective and thus should be worn, countered on the other side by the belief that risk compensation negates this protective effect of helmets. A systematic review on helmet effectiveness has been published in the Cochrane Library. ${ }^{1}$ The objective of the Cochrane review was to determine whether bicycle helmets reduce head, brain, and facial injury for bicyclists of all ages involved in a crash. The principles required of high quality evidence based reviews were followed: a comprehensive literature search, pre-established study selection criteria, and most importantly a critical review of study methods. A well conducted systematic review identifies and considers all the literature (peer reviewed, government reports, and unpublished papers), and rates the study quality. Appropriately, such reviews only include better designed and conducted studies. The evidence is then summarized across all the studies.

The literature search for the Cochrane review yielded five studies meeting the preestablished criteria for inclusion. The strengths and weaknesses of five case-control studies of bicycle helmet effectiveness were carefully evaluated. The scientific evidence which indicates that bicycle helmets protect against head, brain, severe brain and facial (upper and midface) injuries has been well established. Additionally, the evidence indicates that helmets provide injury protection in all type of crashes including those involving motor vehicles.

Based on this review the authors recommended that as a policy bicycle riders of all ages should be encouraged to wear helmets. The purpose of publishing health research, and discourse about it, is to improve the health of the public. We believe that the evidence indicates such a strong protective effective of helmets, that the net effect on the health of the public will be positive.

\section{What about the theory of risk compensation?}

WHAT IS RISK COMPENSATION?

Risk compensation is frequently raised during debates about helmet promotion and legislation. Briefly put, risk compensation theory suggests that individuals provided with a protective device such as a bicycle helmet or an automobile seat belt will act in a riskier manner because of the sense of increased protection from the helmet or seat belt and thereby nullify the protection afforded by the helmet or seat belt. The theory of risk compensation is not applicable to case-control studies of helmet effectiveness per se. Its potential applicability is to the impact of widespread use of helmets, particularly legislation to require helmet use, and its net protective effect.

WHAT ARE THE ARGUMENTS FOR RISK COMPENSATION?

The theories of risk homeostasis and risk compensation are well summarized by Gerald Wilde and John Adams. ${ }^{2-4}$ Those who argue that risk compensation must be taken into account before bicycle helmets are adopted as a safety measure have said:

(1) Encouraging helmet use would have serious adverse consequences on the public health, without making any significant difference to the dangers of riding. ${ }^{5}$

(2) Wearing of a helmet influences cyclists' behaviour, thereby affecting the likelihood of them being involved in such an incident in the first place. Cyclists are less likely to ride cautiously when wearing a helmet owing to their feeling of increased security. In this way, they consume some, if not all, of the benefit that would otherwise accrue from wearing a helmet. ${ }^{6} 7$

There have been no systematic reviews of the evidence for the relevance of risk compensation to bike helmets. Mayer Hillman states the evidence for risk compensation is "overwhelming". 6

WHAT EMPIRICAL EVIDENCE EXISTS FOR RISK COMPENSATION BEHAVIOUR?

If risk compensation plays a role, one would expect the gains from helmet effectiveness to be erased or strongly mitigated by increasingly risky riding habits of helmet wearers which would neutralize any protective effect provided by helmet wearing. What do the empiric data show?

(A) Bicycle riders

The evidence from time series studies in Australia, New Zealand, Europe, and the United States indicates that increased rates of
Ninth Avenue, Seattle, WA 98104, USA

dct@u.washington.edu 
helmet use resulting from multifaceted educational campaigns and/or legislation are linked to significant decreases in bicycle related head injuries. ${ }^{8-13}$ Given that helmets are very effective, cyclists would have to increase their risk taking fourfold to overcome the protective effect of helmets. This seems unlikely.

\section{(B) Motorcycle riders}

The closest analogy to bicycle helmet use is mandatory motorcycle helmet use laws in the United States. Although there is general agreement that motorcycle helmets reduce head and brain injury when a crash occurs, many motorcyclists dislike helmets. Risk compensation theory would propose that a motorcyclist might drive more recklessly if legislation requires helmet use. Motorcyclists may also be considered vulnerable road users, since motorcycle crashes usually result in serious injury to the motorcyclists themselves and not to cars and other motor vehicle passengers. In the United States nearly all 50 states passed laws requiring motorcycle helmets in the mid1960s. In 1976 almost half of the states repealed their laws. This provided an opportunity for a natural experiment. Fewer motorcyclists wore helmets following the repeal of motorcycle helmet laws. This resulted in a $25 \%$ to $40 \%$ increase in motorcycle deaths. ${ }^{14-18}$ These results strongly imply that wearing a helmet does NOT lead to large increases in risk taking. ${ }^{18}$

\section{(C) Motor vehicle drivers and passengers}

An extensive systematic review of automobile safety interventions by the non-federal national Community Preventive Services Task Force has been sponsored by the Centers for Disease Control and Prevention since 1996. The task force looks at both the benefits and the risk for any given intervention. Based on results of systematic reviews, the task force makes recommendations on population based interventions to promote health and prevent disease, injury, disability and premature death, and to reduce environmental hazards. The task force found that child safety seats, seat belts, and alcohol laws all contributed to substantial reductions in motor vehicle injuries and deaths. The task force recommended a number of communitywide information and enforcement campaigns to promote these measures. ${ }^{19}$

Based on risk composition theory, John Adams has long opposed seat belt legislation. ${ }^{34}$ The Adams essay published on the Cato Institute web site discusses risk compensation and seat belt legislation. The essay explains the theory of risk management and uncertainty but it is not a critical systematic review. Information on the United States experience with seat belt legislation is omitted from the discussion. The reason provided in reference number 3 , is that "calls by Cato staff to the National Highway Traffic Safety Administration to obtain research results about how many lives have been saved through seat belt use were unsuccessful". ${ }^{4}$ However, this information is available to the public from the National Technical Information Service, Springfield, Virginia. It is also indexed in the Transportation Research Information Service (TRIS) database. ${ }^{2021}$ Authors of a systematic review would obtain and evaluate all available research before arriving at a conclusion.

\section{Summary and conclusion on risk compensation theory arguments}

In summary the empirical evidence to support the risk compensation theory is limited if not absent. There are a number of studies in the traffic literature that point out problems or show data at odds with the risk compensation/ homeostasis theory. No systematic review of the evidence for risk homeostasis has been conducted.

We recommend that interested readers consult a comprehensive discussion of the risk compensation debate presented by James Hedlund at the Fifth World Conference on Injury Prevention and Control. ${ }^{22}$ James Hedlund provided his personal view: "I believe the evidence is overwhelming that every safety law or regulation is not counterbalanced by compensating behavior". We suggest risk compensation is an appropriate area for systematic reviews.

\section{Conclusions on recommending the use of bicycle helmets}

Based on the solid empirical evidence for bicycle safety helmet effectiveness, we are confident in recommending their use, and policies to encourage their use. However, additional criticisms of our Cochrane review have been raised by Bill Curnow and Dorothy Robinson. These criticisms and our replies are published on the Cochrane injuries group web site (http:// www.cochrane-injuries.ich.ucl.ac.uk/

HelmetComment.htm). Criticisms from Richard Keatinge and Mayer Hillman will be published along with author's replies in the next edition of the Cochrane reviews. Please read this series of interesting debates. In our opinion, we have provided well founded answers to the criticisms.

We feel there is strong scientific evidence for recommending or mandating bicycle helmet use. This is a first step in reducing bicycle related head injuries. Encouraging cycling, building a bicycle friendly infrastructure, and promoting safe cycling instruction are also important activities. These activities are not mutually exclusive. Promoting bicycle helmet use does not exclude other road safety approaches. There are many aspects to bicycle injury prevention, helmet use is just one technique, one which has proven effective.

\footnotetext{
1 Thompson DC, Rivara FP, Thompson R. Helmets for preventing head and facial injuries in bicyclists (Cochrane review). The Cochrane Library, Issue 3, 2000. Oxford: Update Software.

2 Wilde G. Target risk. Toronto: PDE Publications, 1994.

3 Adams J. Risk. London: UCL Press, 1995.

4 Adams J. Cars, cholera and cows: the management of risk and uncertainty. Washington, DC: Cato Institute, No 335, 1999. http://www.cato.org/pubs/pas/pa-335es.html
} 
Keatinge R. Comment 3, Cochrane injuries group web site 2001. $2001 . \quad$ http://w

6 Hillman M. Comment 4, Cochrane injuries group web site 2001. http://www.cochrane-injuries.ich.ucl.ac.uk/ HelmetComment.htm.

7 Hillman M. Cycle helmets: the case for and against. London: Policy Studies Institute, 1993.

8 Vulcan AP, Cameron MH, Watson WL. Mandatory bicycle helmet use: experience in Victoria, Australia. World $\mathcal{F}$ Surg 1992;16:389-97.

9 Carr D, Skalova M, Cameron M. Evaluation of the bicycle helmet wearing law in Victoria during its first four years. No 76. Melbourne: Monash University Accident Research Center, 1995.

10 Pitt WR, Thomas S, Nixon J, et al. Trends in head injuries among child bicyclists. BMF 1994;309:877.

11 Ekman R, Schelp L, Welander G, et al. Can a combination of local, regional and national information substantially increase bicycle-helmet wearing and reduce injuries? increase bicycle-helmet wearing and reduce injuries?
Experience from Sweden. Accid Anal Prev 1997;29:321-8.

Experience from Sweden. Accid Anal Prev 1997;29:321-8.
12 Rivara FP, Thompson DC, Patterson MQ, et al. Prevention Rivara FP, Thompson DC, Patterson $\mathrm{MQ}$, et al. Prevention
of bicycle-related injuries: helmets, education, and legislation. Annu Rev Public Health 1998:19:293-318.

13 Scuffham P, Alsop J, Cryer C, et al. Head injuries to bicyclists and the New Zealand bicycle helmet law. Accid Anal Prev 2000;32:565-73.

14 Evans L. Traffic safety and the driver. New York, NY: Van Nostrand Reinhold, 1991.

15 General Accounting Office. Highway safety: motorcycle helmet laws save lives and reduce costs to society. Washington, DC: US General Accounting Office, 1991.

16 Fleming HS, Becker ER. The impact of the Texas 1989 motorcycle helmet law on total and head-related fatalities, severe injuries, and overall injuries. Med Care 1992;30:83245 .

17 Kraus JR, Peek C, McArthur DL, et al. The effect of the 1992 Calfornia motorcycle helmet usage law on motorcy-
cle crash fatalities and injuries. FAMA 1994;272:1506-11.

18 Evans L. Cycle helmets and the law: even when the science is clear policy decisions may still be difficult BMF 1994;308:1521-2.

19 US Community Preventive Services Task Force recommendations. MMWR Morb Mortal Wkly Rep 2001 (in press).

20 National Highway Traffic Safety Administration. Fourth report to congress: effectiveness of occupant protection systems and their use. Washington, DC: NHTSA, May 1999.

21 National Highway Traffic Safety Administration. Effectiveness of lap/shoulder belts in the back outboard seating positions. (DOT HS 808945 NHTSA technical report.) Washington, DC: NHTSA, June 1999

22 Hedlund J. Risky business: safety regulations, risk compensation, and individual behavior. Inj Prev 2000;6:82-90.

\section{Response from Adams and Hillman}

We did NOT accept that bicycle helmets are effective in reducing head injuries. We had hoped that by putting it in italics they would have noticed our rider in the event of an accident. For evidence of their predisposition also to include inadequate science supportive of their argument see our letter in the $B M \mathcal{F}^{1}{ }^{1}$

We wish them luck in their systematic review of all the tens of thousands of articles that have a bearing on risk compensation. In undertaking this review we suggest that in devising inclusion and exclusion criteria for their more refined filters they be wary of the following:

- Studies that deal with small subsets of populations - such as the oft cited study of admissions to 16 hospitals in Sweden after the introduction of a seat belt law, which concluded that the law had reduced injuries and fatalities. The fact that in Sweden as a whole the number of deaths and injuries suffered by car occupants increased after the law suggests that it must have been possible to find other sets of hospitals which found the opposite result. ${ }^{2}$

- Claims based on statistical significance. One time in 20 researchers who use the conventional $5 \%$ test of significance will find "significance" by chance. Given the well known desire of researchers to "prove" their hypotheses, one in 20 is probably a generous estimate of the ratio of tests published to tests done.

- Studies that ignore system effects. Prohibiting motorcycling, for example, would prevent the loss of lives in motorcycle accidents. But to demonstrate that it had saved lives one would have to track the alternative forms of transport and thrill seeking adopted by the banned motorcyclists-everything from sky diving to driving old bangers in a way that pumps as much adrenaline.

- Empirical evidence of risk compensation. In Britain there is one cycling fatality for every 25 million kilometres cycled-not all of them of course due to head injuries. The risk compensating behaviour required to offset the claimed benefits of helmets would require an extra fatal error once in many millions of kilometres - a behavioural change unlikely to be directly observable.

Hedlund, whom they cite respectfully, having surveyed the debate about risk compensation, says "if experiments cannot provide useful evidence, and if evaluations are contaminated by poor data and uncontrolled factors, we are left with theory". The theory supporting risk compensation is well supported by empirical evidence in cases where the risks are large: trapeze artists will attempt manoeuvres with safety nets that they would not contemplate without them. The contention of those who would introduce measures that would criminalize self risk (for example, riding without a helmet) is that this effect vanishes when the risk is smaller. Given the dismal record of the prohibitionists, we suggest that the burden of proof lies with them.

1 Adams J, Hillman M. Bicycle helmets. BMF 2001;322:1063-4.

2 Adams J. Risk. London: UCL Press Ltd, 1995: 113-34. 